\title{
EL PROCESO DEPURADOR EN LA ENSEÑANZA PRIMARIA DURANTE LA ESPAÑA FRANQUISTA: UN ESTUDIO DE CASO EN LA PROVINCIA DE SANTA CRUZ DE TENERIFE
}

\author{
Manuel Ferraz Lorenzo ${ }^{1}$
}

\section{RESUMEN}

El trabajo que presentamos trata de analizar el proceso depurador desarrollado en la enseñanza primaria a partir de julio de 1936. Tengamos presente que el golpe de Estado irrumpe en la provincia de Santa Cruz de Tenerife y que las medidas represoras debían ser contundentes y ejemplarizantes para el resto de las zonas sometidas con posterioridad. Además de las autoridades políticas, los maestros fueron uno de los colectivos más perseguidos y reprimidos por sus actuaciones educativas, culturales y sociales. La rapidez y la contundencia en las detenciones y condenas aparecen claramente reflejadas en los documentos civiles y militares consultados. La metodología utilizada se centra en el análisis y la interpretación cualitativa de datos de archivo, de los boletines oficiales y de la prensa consultada.

Palabras clave: dictadura franquista, represión, Canarias, enseñanza primaria, maestros.

${ }^{1}$ Universidad de La Laguna (ULL), Tenerife, Islas Canarias, Espanha. 


\section{O PROCESSO DE PURIFICAÇÃO NO ENSINO PRIMÁRIO DURANTE A ESPANHA DE FRANCO: UM ESTUDO DE CASO NA PROVÍNCIA DE SANTA CRUZ DE TENERIFE}

\section{RESUMO consultada na altura com uma abordagem qualitativa. \\ THE PURIFYING PROCESS IN PRIMARY EDUCATION DURING FRANCO'S SPAIN: A CASE STUDY IN THE PROVINCE OF SANTA CRUZ DE TENERIFE}

O artigo de pesquisa que apresentamos tenta analisar o processo de purificação desenvolvido no ensino primário a partir de julho de 1936. Devemos ter em mente que o golpe de Estado irrompeu na província de Santa Cruz de Tenerife e que as medidas repressivas devem ser contundentes e exemplares para o resto das áreas apresentadas e submetidas posteriormente. Além das autoridades políticas, os professores foram um dos grupos mais perseguidos e reprimidos por suas atividades educacionais, culturais e sociais. A rapidez e a força nas prisões e condenações estão claramente refletidas nos documentos civis e militares. A metodologia utilizada centra-se na análise e interpretação de dados arquivísticos, boletins oficiais e imprensa

Palavras-chave: ditadura franquista, repressão, Ilhas Canárias, educação primária.

\section{ABSTRACT}

The paper that we present tries to analyze the repression process developed in the primary education from July of 1936 . We need to take into consideration that the coup d'état broke out in the province of Santa Cruz de Tenerife and that the repressive measures should be conclusive and exemplary for the rest of the areas submitted afterwards. In addition to the political authorities, teachers were one of the groups most persecuted and repressed for their educational, cultural and social activities. The speed and forcefulness of the arrests and convictions are clearly reflected in the civil and military documents. The methodology used focuses on the analysis and interpretation of archival data, official bulletins and the press consulted at the time with a qualitative approach.

Keywords: Franco's dictatorship, repression, Canary Islands, primary education, teachers.

\section{LE PROCESSUS DE PURIFICATION DANS L'ENSEIGNEMENT PRIMAIRE PENDANT L'ESPAGNE DE FRANCO. UNE ÉTUDE DE CAS DANS LA PROVINCE DE SANTA CRUZ DE TENERIFE}

\section{RÉSUMÉ}

L'article que nous présentons tente d'analyser le processus de purification développé dans l'enseignement primaire dès juillet 1936. Nous devons garder à l'esprit que le coup d'État entre 
dans la province de Santa Cruz de Tenerife et que les mesures répressives doivent être énergiques et exemplaires pour le reste des zones soumises plus tard. En plus des autorités politiques, les enseignants étaient l'un des groupes les plus persécutés et les plus réprimés pour leurs activités éducatives, culturelles et sociales. La rapidité et la force des arrestations et des condamnations sont clairement reflétées dans les documents civils et militaires. La méthodologie utilisée est axée sur l'analyse et l'interprétation des données d'archives, des bulletins officiels et de la presse consultée à l'époque avec une approche qualitative.

Mots-clés: dictature de Franco, répression, îles Canaries, enseignement primaire, enseignants. 


\section{INTRODUCCIÓN}

Cuando en 1936 se produce la feroz represión sobre los maestros y maestras españoles, no se improvisaba un desafiante amago de porfía a su habitual quehacer; tampoco se ponían en tela de juicio sus acciones y prácticas escolares por considerarlas inadecuadas, ineficientes o poco adaptadas a las demandas doctrinales emergentes; menos aún, se reprobaban sus actitudes por considerar que sus enseñanzas transgredían el modelo de moralidad imperante, cuando, muchos de ellos, habían demostrado una rectitud ética, un compromiso profesional, un respeto por las opiniones contrarias y, sobre todo, un interés denodado por la educación integral y por la construcción de un modelo de ciudadanía independiente, crítico y culto, irreprochables hasta entonces. Lo que se produjo fue una reacción ideológica de profundas raíces clasistas, católicas e hispanas, convertida en acción política de emergencia por parte de los mayores banqueros y propietarios españoles, reforzada con munición militar y paramilitar, y amparada en la incultura de amplios sectores de la población para exaltar la, mal denominada y peor entendida, identidad patriótica (CASANOVA, 2005; FONTANA, 1986; GRAHAM, 2006; JULIÁ, 1999; MORADIELLOS, 2002; PAYNE,1977; PRESTON, 1998; REIG, 1990; VIVES, 1978; VV.AA., 1977; para el caso de Canarias CABRERA, 2000; LEÓN, 2014, 2016; RIVAS, 2015). Con ello, se pretendía demoler todas las reformas sociales, pedagógicas y educativas aceptadas democráticamente desde 1931, recogidas en el ordenamiento jurídico y en el pensamiento dominante de la época de base racional, científico y plural.

Sin embargo, el repliegue al relato hispano, retador, altivo y mesiánico en contra del progreso y de sus hacedores no irrumpió en los años $30 \mathrm{ni}$ procedía de los acuartelamientos castrenses; provenía de comienzos de siglo, por no remontarnos más en el pasado y rastrear buena parte de la literatura reaccionaria del siglo XIX. Como se puede comprobar en una carta de Marcelino Menéndez Pelayo enviada al obispo de Madrid-Alcalá, el año 1910, con motivo del asesinato de Francisco Ferrer i Guardia y de su proyecto de escuela laica, 
queda patente dicha política de consagración a una determinada y excluyente forma de entender el pasado y, por tanto, de anclaje cognoscitivo y de limitación, distorsión y parálisis del pensamiento más avanzado y contrastado intelectualmente:

\begin{abstract}
Lo que pueden dar de sí generaciones educadas con la hiel de la blasfemia en los labios, sin noción de Dios, ni sentimiento de la Patria, ya lo han mostrado con ejemplar lección sucesos reciente, ante los cuales el silencio parecería complicidad, o por lo menos cobardía. Por eso, yo, que soy uno de tantos católicos españoles, sin autoridad para levantar la voz ante mis conciudadanos, he escrito estas líneas con el único fin de hacer constar mi adhesión a la protesta cristiana y española que elocuentes voces han de formular mañana (INSTITUTO, 1938, p. 11).
\end{abstract}

Pues bien, ese mañana del que hablaba Menéndez Pelayo, que tuvo un esporádico estallido en 1923 y algunos brotes sin consecuencias políticas a comienzos de los años 30, se convirtió en insoportable escenario de actuaciones para muchos ciudadanos españoles a partir de 1936. Sin embargo, lo preocupante no es que se hiciera realidad a golpe de terror y crueldad humanas en sus manifestaciones cotidianas, sino que se convirtiera en legalidad y que, al cobijo de ésta, se persiguieran como delictivas, perniciosas e inmorales conductas que, sólo unos meses antes, habían sido ejemplares y dignas de todo tipo de elogios.

El "colofón" a esta deriva educativa, cultural y social estuvo en la Ley de Educación Primaria de 17 de julio de 1945. En su exposición de motivos, el Jefe de Estado firmante retomaba una interpretación torticera y gramaticalmente barroca de la tradición, para afirmar que, "contra la falsía de los improperios y el acerbo vituperar de los que la ignoran o cínicamente la contradicen, la gloriosa tradición pedagógica hispana representa uno de los caudales más valiosos de nuestro haber histórico y una de las más preciadas aportaciones a la cultura ecuménica". Algunas líneas más adelante la ley proseguía con la idea de consolidar las conquistas realizadas por el régimen: "acometer esta gran 
empresa [...] significa la supervivencia del espíritu del Movimiento en el futuro de España a través de las generaciones infantiles que son hoy esperanza y mañana realidad". Por último, su artículo 15 no dejaba dudas sobre el nuevo ideario conservador, católico e hispano que establecía, recordando en su enunciado -aunque sólo sea como referencia remota- las Partidas de Alfonso X, publicadas durante el siglo XIII: "La escuela es la comunidad activa de Maestros y escolares instituida por la Familia, la Iglesia o el Estado; como órgano de la educación primaria para la formación cristiana, patriótica e intelectual de la niñez española" (BOE, 1945).

Pero para poder llegar a esta ley, y a la realidad que la permitía y la demandaba, hubo que allanar el camino durante los 8 años anteriores. Ello significó emplear los más bárbaros e implacables métodos de depuración, coerción, represión y violencia que jamás se habían utilizado para anular al adversario; también significó crear el debido temor entre los que pensaban y actuaban "fuera" de las leyes creadas ad hoc, o al margen de lo expuesto en las proclamas, sermones y bandos de los poderes imperantes, carentes de cualquier tipo de legitimidad democrática. Aunque es cierto que la represión franquista ha sido objeto de estudio por parte de muchos investigadores que han centrado sus trabajos en las tres etapas educativas formales (primaria, secundaria y universidad), (MORENTE, 1997; GRANA, 2005 y CLARET, 2006), al entender que las escuelas, los institutos y las universidades fueron instituciones que sirvieron de mecanismos privilegiados de socialización política, ideológica y cultural (MAYORDOMO; FERNÁNDEZ, 1993; MAYORDOMO, 1999), no es menos cierto que todavía quedan archivos por consultar, documentación por revisar y territorios por explorar, como partes del conjunto estatal ${ }^{2}$. Nuestro trabajo tiene por objeto completar la visión que otros estudios previos han mostrado sobre la represión de la enseñanza primaria, en un contexto periférico y fragmentado como el canario -dada la lejanía y la insularidad de su territorio-

\footnotetext{
2 Este estudio va a dedicar una atención especial a la documentación extraída del Archivo Intermedio Militar de Canarias (de ahora en adelante AIMC) y del Archivo de la Inspección de Educación Primaria de Santa Cruz de Tenerife (Aiep). Debemos comentar que, hasta ahora y para investigar esta temática, no se han tenido en consideración sus fondos documentales.
} 
que sirvió de laboratorio de experimentación en las actuaciones de dominación de otras zonas sometidas con posterioridad 3 . Y es que Canarias, como una de las cunas del golpe de Estado y de la posterior guerra civil, comenzó sus medidas depuradoras de manera prematura, favorecidas en mandatos, ordenanzas, mensajes telegrafiados y, por supuesto, delaciones particulares, al margen de cualquier normativa de rango superior por irracional, ilegítima e intimidatoria que ésta fuera. Para abordar esta temática, la metodología que hemos utilizado se centra en la revisión, análisis e interpretación de datos bibliográficos, de archivo, de los boletines oficiales y de la prensa de la época consultada, con un enfoque cualitativo en su tratamiento. Además, para evidenciar los argumentos expuestos y darles un carácter más riguroso, nos hemos auxiliado continuamente de citas y referencias, siendo frecuentes los testimonios, las apoyaturas y las aclaraciones realizadas a pie de página.

\section{FASE INICIAL. CONTUNDENCIA REPRESORA Y CONSECUENCIAS SOCIALES Y PERSONALES}

El 18 de julio de 1936, a las 5 de la mañana, el General de División Comandante Militar de las Islas Canarias, Francisco Franco Bahamonde, emitía un bando en el que declaraba el Estado de Guerra en todo el Archipiélago. En el artículo 9 aludía a los funcionarios públicos y demás corporaciones civiles, exigiéndoles el "inmediato auxilio" para el restablecimiento del orden y, añadía a continuación, para quienes no lo hicieran, que "serán suspendidos en el acto de empleo, cargos y sueldos o gratificaciones anexos, sin perjuicio de las responsabilidades en que incurrieren" (BOP, 1936a). Aquel Bando, con su inicial

\footnotetext{
3 Cuando se aprobaron las leyes de gran calado represor, como la de Responsabilidades Políticas de 9 de febrero de 1939 (BOE 13-II-1939, núm. 44), la de Depuración de funcionarios públicos de 10 de febrero de 1939 (BOE 14-II-1939, núm. 45), o la de Represión de la masonería y el comunismo de 1 de marzo de 1940 (BOE 2-III-1940, núm. 62), en las Islas ya se revisaban las condenas impuestas desde los momentos iniciales del golpe militar por los mismos delitos que éstas, y otras leyes, condenaban (como también ocurrió en otras zonas prontamente sometidas tras el pronunciamiento militar). Los trabajos pioneros, en cuanto a la represión del magisterio canario se refiere, son los siguientes: Ferraz, 1997; Hernández, 1989; Negrín, 2010.
} 
"Ordeno y mando", sería el punto de partida de la persecución en la que se verían implicados todos los cargos públicos de las Islas, incluyendo en ellos a los docentes. Fue así como el 1 de agosto de 1936, apenas 14 días después de producido el golpe de Estado y en plenas vacaciones de verano, el Jefe de la sección administrativa de primera enseñanza de la provincia, Arturo PérezZamora y Mandillo, se dirigía al Coronel Jefe del Estado Mayor de la Comandancia Militar de las Islas Canarias, Teódulo González Peral, a través de un oficio en el que señalaba la realidad de las primeras detenciones: "Tiene conocimiento particular el Jefe que autoriza de que son varios los Maestros Nacionales que en la actualidad se encuentran detenidos por mandato de Autoridad competente para ello, por suponerles encontrarse complicados en el movimiento político actual". Lo que deseaba saber el responsable de la enseñanza en la provincia era si debía abonarles el salario por las actuaciones mantenidas en el pasado más reciente. Las indicaciones del Coronel Jefe como Comandante Militar -y como máximo responsable del proceso depurador llevado en las Islas-, en la respuesta escrita de su puño y letra, no ofrecían dudas al respecto: La ausencia, esto es, el no personarse durante el cobro de sus haberes y el no haber mostrado adhesión a la causa nacional desde sus orígenes, eran motivos más que suficientes para que los docentes dejaran de percibir su salario4. Fue la primera actuación represiva que recayó sobre ellos.

Pero este despropósito intimidatorio y persecutorio de las nuevas autoridades no había hecho más que comenzar. Era mucho el trabajo que se acumulaba desde los momentos iniciales de la contienda pues había sospechas de que centenares de docentes habían secundado las reformas republicanas y de que, algunos de ellos, habían sido miembros, y habían participado activamente, en partidos políticos y sindicatos vinculados al Frente Popular. Así que pocos días después, en concreto el 7 de agosto, y bajo el mandato del Gobernador Civil de la provincia, Julio Fuentes Serrano, se creaba una Junta Informativa y

\footnotetext{
4 Documentación de la Secretaría particular y general de la Comandancia Militar de Canarias (1936-1939). Sanciones a los maestros de primera enseñanza de la Provincia de Santa Cruz de Tenerife. Caja 1.731, Carpeta 32. AIMC.
} 
Asesora con amplias funciones delatoras, que recababa la información de los alcaldes, guardia civil y jefes de acción ciudadana, con el objetivo, en principio, de investigar y perseguir a los miembros de la Fete, aunque con posterioridad se amplió a todos los docentes para conocer con certeza si se habían adherido a la causa nacional.

Como se puede comprobar, la depuración fue muy rápida y contundente si tenemos presente que a mediados de septiembre ya se habían enviado al Boletín Oficial de la Provincia, por parte de la Sección Administrativa de Primera Enseñanza y previa aprobación de la Comandancia Militar, los dos primeros listados de maestros y maestras represaliados. En ellos aparecían un total de 108 docentes (27 mujeres), con la referencia de la escuela que habían regentado y la sanción establecida por la autoridad cívico-militar correspondiente. Dichas sanciones disponían la separación definitiva de la enseñanza, con baja en el escalafón y nulidad del título (a veces denominada también como "incapacidad para ejercer la enseñanza con nulidad del título profesional"); incapacidad para ejercer la enseñanza con pérdida de la escuela e inhabilitación durante 4 años para regentarlas; pérdida de la escuela e inhabilitación durante 3, 2 o 1 año; separación del servicio durante un año y pérdida de la escuela; condenas de 10 meses sin sueldo; sanción del $50 \%$ de su sueldo durante 9, 6, 4, 3 meses o, las más benignas, 2 meses (BOP, 1936b; 1936c).

En paralelo, la Sección administrativa de primera enseñanza, de acuerdo con el Gobernador civil de la provincia y de la Comandancia Militar -ya en manos del temido general Ángel Dolla Lahoz-, emitía un anuncio el 5 de septiembre. En el mismo, se modificaba el modo de proveer las interinidades a las escuelas nacionales, "siendo una de las causas que lo motivan el que de las instancias presentes, algunas de ellas no son acreedoras a regentar destinos por las ideas políticas que sustentan" (BOP, 1936d)5.

5 Tal y como asegura Aarón León, "Su estancia en Canarias ha sido recordada fundamentalmente por la intensidad de la fase represiva vivida en esos momentos y se tradujo, 
Pero además de aquellos docentes, había otros que también estaban en el punto de mira de las autoridades. Con fecha 6 de octubre aparecieron los primeros nombres en los informes de las autoridades militares y de las comisiones depuradoras creadas a tal efecto. Dicha notificación oficial estaba firmada por el Gobernador Civil, la Inspectora Jefe de primera enseñanza, dos directores de la Asociación de padres de familia y el Jefe de la Sección administrativa de la primera enseñanza ${ }^{6}$, y señalaba los derroteros que les deparaba a decenas de maestros y maestras. Esta relación de nombres se incluyó en los nuevos listados de docentes depurados que se publicó con posterioridad. Dos días más tarde aparecía otro listado con 9 enseñantes que ejercían su profesión en Santa Cruz de Tenerife y otro en Candelaria; entre ellos, había tres mujeres. Simultáneamente, el Comité militar de la Gomera suspendía de empleo y sueldo a Bernardo Vega y la Comandancia Militar de La Palma quiso hacer lo propio con el maestro de Tazacorte, Enrique Francés, pero dado el período estival en el que todos estos sucesos tuvieron lugar, el mencionado maestro se encontraba de vacaciones en Valencia y nunca más regresó a la Isla. Todos estos nombres fueron incluidos también en los listados publicados en los posteriores BOP.

Sin embargo, y pese a las medidas tempranas - muchas veces preventivas, prematuras e injustificadas - impulsadas para reprimir a los docentes, estas depuraciones y sanciones sugeridas por la Junta Informativa y Asesora, y avaladas por el Gobierno civil, no eran suficientes para el nuevo Comandante Militar de Canarias que solicitaba más contundencia contra los maestros7. No en vano, el 30 de octubre de 1936, el propio Dolla, publicaba un

entre otras cosas, en la desaparición de cientos de personas" (LEÓN, 2016, p. 88).

6 "Estado comprensivo de los maestros nacionales a quienes se deben imponer las sanciones que se indican". Documentación de la Secretaría particular y general de la Comandancia Militar de Canarias (1936-1939). Sanciones a los maestros de primera enseñanza de la provincia de Santa Cruz de Tenerife. Caja 1.731, Carpeta 32. AIMC.

7 Tengamos muy presente el impacto que causó el decreto de cese colectivo publicado el 27 de septiembre de 1936, emitido por la Junta de Defensa Nacional de Burgos. Dicho cese afectaba a 1.566 maestros de las dos provincias canarias. Aunque de entrada nos parece una cifra exagerada que pretendía dar cuenta de la contundencia de la represión, sí es cierto que muestra la preocupación que existía sobre la labor desarrollada en Canarias por sus docentes 
Bando en el que creaba el cargo de Delegado de la Autoridad militar de la Enseñanza primaria, pública y privada y de Escuelas Normales del Archipiélago, que tenía como atribuciones - entre otras - las de "inspeccionar la labor docente de los Maestros de Primera Enseñanza, profesores particulares y de Escuelas Normales de todas las Islas Canarias" y "proponer la suspensión de empleo y sueldo o la formación de expedientes contra aquellos maestros o profesores que no considere conveniente sigan al frente de sus Escuelas por ser su labor contraria a las normas del nuevo Estado". Se militarizaba, a partir de entonces, toda la actividad escolar desarrollada en las Islas que pasaba a manos de Luis López Ayala, Capitán de Artillería y Marqués de Villafuerte8. Ante la contundencia que pedía el Comandante General, observemos los argumentos más "morigerados" que esgrimía el Gobernador civil en su escrito de respuesta, con fecha de 18 de noviembre.

\begin{abstract}
Refiriéndome a la denuncia formulada a su Superioridad sobre la necesidad de hacer una depuración más radical de estos profesionales, me permito objetarle que la Junta Informativa y Asesora encargada de hacer esa depuración, se ha atenido en todo momento a los informes que se han recibido de los Sres. Alcaldes, Jefes de Acción Ciudadana y Comandantes de los Puestos de la Guardia Civil, y no puede escapar a su clarividente comprensión todo lo difícil que es aquilatar hasta la perfección los méritos y defectos de todos los maestros que ejercen en la Provincia9.
\end{abstract}

Pese al intento por llevar a las escuelas primarias "personal idóneo", que

durante el período republicano (ALTED, 1984, p. 168).

${ }^{8} \mathrm{El}$ encabezado del Bando decía lo siguiente: "[...] Teniendo en cuenta la necesidad de que los futuros hombres del Estado sean educados en aquellos principios religiosos y nacionales consustanciales con la grandeza de la Patria y que por otra parte del Magisterio primario le sea suministrada la cultura más a propósito para desarrollar en ellos el temor a Dios y el amor de España, se hace preciso el nombramiento de un Delegado de mi Autoridad [...]". "Bando sobre las Escuelas normales y primarias de la Región". Documentación de la Secretaría particular y general de la Comandancia Militar de Canarias (1936-1939). 30 de octubre de 1936. Caja 1735, Carpeta 7. AIMC. Véase, también, Gaceta (1936). En este diario aparecía explícito el sentir católico que debía guiar la enseñanza a partir de entonces.

9 "Carta del Gobernador Civil de la Provincia de Santa Cruz de Tenerife al Comandante Militar de Canarias". Documentación de la Secretaría particular y general de la Comandancia Militar de Canarias (1936-1939). Sanciones a los maestros de primera enseñanza de la provincia de Santa Cruz de Tenerife. Caja 1.731, Carpeta 32. AIMC. 
a sus condiciones culturales demostrara virtudes de tipo moral y "acendrado españolismo", el Gobernador Civil sugería que para "hacer una más exquisita selección" (sic), se debían renovar los Consejos Locales. Estos órganos municipales conocían perfectamente a todos los maestros y maestras de la zona objeto de su influencia. Y así fue como pocos días después, el Gobernador Civil daba la orden pertinente a los alcaldes para sustituir los Consejos por Juntas. Sus argumentos daban cuenta de la minuciosidad que reclamaba para concluir adecuadamente todo el proceso depurador emprendido:

Sin embargo, y dadas las dificultades con que se ha tropezado para adquirir antecedentes exactos de los referidos maestros, ha podido muy bien suceder que haya escapado a la depuración hecha por la Junta correspondiente, alguno de estos profesionales que si no sanción determinada, necesite, cuando menos, la estrecha vigilancia de autoridades y vecinos de confianza absoluta en los distintos pueblos, que se encarguen de seguir de cerca no sólo su proceder profesional, sino también el social, político e incluso el particular, ya que estas cualidades de los maestros son casi siempre tomadas como ejemplo para el niño. En consecuencia a este fin, se acordó sustituir los Consejos por Juntas Locales de Primera Enseñanza, cuya función principal es la que se indica anteriormente ${ }^{10}$.

A pesar de la irrupción represora de los primeros momentos, fue a partir de entonces (comienzos de noviembre) cuando las depuraciones aumentaron en número y en sanciones. Como se puede comprobar en otro documento elaborado y firmado por el Gobernador Civil, la Inspectora Jefe de primera enseñanza, el Jefe de la sección administrativa de primera enseñanza y dos directivos de la Asociación de padres de familia, se presentaba una relación de 80 docentes depurados, 36 de los cuales eran mujeres. Las sanciones en esta ocasión oscilaban entre la separación definitiva (sobre todo para aquellos que estaban en zona republicana y no se habían presentado a sus escuelas en Canarias) y la suspensión de empleo y sueldo, o la rebaja de este por un tiempo limitado que solía establecerse entre los dos años y los dos meses. Antes, se

\footnotetext{
${ }^{10}$ Firmado en noviembre, pero sin fecha exacta (Ibidem).
} 
había publicado otra relación en el BOP que hacía referencia a los docentes represaliados con fecha de 6 de octubre; se trataba de imponerles penas definitivas a los maestros depurados en agosto. El total de maestros que contenía en esta ocasión el listado del BOP era de 24; de ellos, 3 maestras (BOP, 1936e). Pero faltaba otra relación de perseguidos por las nuevas autoridades que apareció justo un mes después. En esta última ocasión figuraban en el BOP 79 docentes (34 mujeres). Las condenas, como en anteriores ocasiones, se fijaban entre la separación definitiva y nulidad de su título profesional, la suspensión de empleo y sueldo durante un año, y la suspensión de medio sueldo por temporadas que oscilaban entre 10 meses y 30 días (BOP, 1936f).

Sin pausa continuaban las delaciones, las denuncias, las persecuciones y las sanciones "de los envenenadores del alma popular" (sic) amparadas ya en la Circular de 7 de diciembre de 1936 de la Comisión de Cultura y Enseñanza, presidida y firmada por José María Pemán, redactada por Eugenio Vega Latapie (vocal de la misma) y dirigida a los Vocales de las Comisiones Depuradoras de Instrucción Pública (BOE, 1936) ${ }^{11}$. Pero también comenzaba ahora, para los que podían hacerlo, los pliegos de descargo y de responsabilidades. Veamos un par de ejemplos: en primer lugar, tenemos el caso del maestro José Delgado Marrero (Güímar, Tenerife), quien, pese a testimoniar su conducta de "patriótica, religiosa y de intensa labor educadora dentro de las normas cristianas", como afirmaban más de 50 vecinos que lo apoyaban, era acusado sin rodeos de concubinato y adulterio por convivir con Concepción Sanfiel Hernández, otra maestra del pueblo ex-alumna suya, "con grave escándalo para sus alumnos, Flechas y público en general, porque el hecho es muy notorio e inmoral para los cargos que desempeña", comunicaba José Soler, Jefe de la guardia civil, a la superioridad militar. Éste era el mismo maestro que, en ausencia de sacerdotes, sería designado por el Vicario General para dar clases de religión en distintos colegios de la Isla ${ }^{12}$. La respuesta de la Inspectora Jefe al

\footnotetext{
${ }^{11}$ Derogada, debido a su contundencia terminológica, por Orden de 17 de febrero de 1937.

12 Para tener en cuenta el papel desempeñado por la Iglesia en la represión efectuada sobre los maestros canarios, véase, Ferraz (2010).
} 
Rector de la Universidad fue contundente: "Considerando lo trascendental de la misión atribuida al Sr. Delgado, esta inspección, velando por el prestigio del Magisterio, se atreve a exponer a V.I. la conveniencia de cerciorarse, antes de conceder la autorización pedida, si a dicho maestro le adornan esas dotes de conducta moral intachable y ortodoxia católica, sin las cuales su actuación sería verdaderamente lamentable"13. Otro caso distinto, pero paralelo, es el del maestro Francisco Orta Madrid (Hermigua, La Gomera), que echaba mano de amigos y antiguos contactos, afines ahora a los nuevos responsables en el poder. En esta ocasión, solicitó certificados de buena conducta al director de las Escuelas del Sagrado Corazón de Huelva, donde había estudiado, del mismísimo Vizconde de La Palma del Condado, de su hermano José, Jefe de Falange en Huelva, o del cura párroco de Hermigua, quienes intercedieron por él y facilitaron la revisión de su condena de suspensión de empleo y sueldo durante un año y pérdida de la escuela que regentaba. Sólo el alcalde y el comandante del puesto de la guardia civil mostraron sus dudas al respecto, al haber participado, según exponían, en mítines a favor del Frente Popular.

Por estas mismas fechas, y junto a las sanciones y pliegos de descargo, se había procedido a incautar material de enseñanza y libros de todo tipo de librería expoliadas por miembros de Falange y Acción Ciudadana. Había que limpiar la enseñanza por todos los medios posibles. Por orden del Coronel Jefe del Estado Mayor, de 5 de noviembre, debía distribuirse dicho material en las academias regimentales y el sobrante entre las escuelas públicas, los institutos y los establecimientos de beneficencia. De nada sirvió el escrito enviado por la inspectora jefe al comandante general de Canarias, de fecha 19 de noviembre, en

\footnotetext{
13 Respuesta de la Inspectora Jefe al Rector de la ULL, tras la petición cursada por el maestro a propuesta del Vicario general, 27 de octubre de 1936. Aiep. Aquella mancha quedaría indeleble en su expediente. En 1939 quiso pedir traslado a otros territorios peninsulares y se le denegó por parte del Inspector Jefe accidental. Estos fueron sus argumentos: "Aunque es innegable su adhesión al Glorioso Alzamiento [...] su estado civil le coloca en una situación que le dificultaría en sumo grado desempeñar puestos de responsabilidad o confianza. Si bien separarlo de su segunda mujer, por medio de un traslado, evitaría el espectáculo deplorable que representa esa unión no santificada por la Iglesia, al deshacer esa familia quedarían sin la autoridad del padre los varios hijos de este segundo matrimonio, con lo cual se crearía un nuevo mal, acaso de funestos resultados". 2 de junio de 1939. Aiep.
} 
el que le exponía que:

Ha llegado a conocimiento de esta Inspección que, en virtud de órdenes superiores emanadas de las Autoridades competentes, han sido requisadas las existencias de varias librerías de esta capital. Entre los objetos incautados se hallarán seguramente algunos de inmediata aplicación a la $1^{\text {a }}$ Enseñanza.

Por esto, y teniendo en cuenta la penuria de material característica de las escuelas nacionales, esta Inspección se atreve a sugerir a V.E. la idea de que el material escolar aprovechable objeto de las requisas, sea distribuido por conducto de ésta, entre las escuelas más necesitadas ${ }^{14}$.

En su respuesta, el Coronel Jefe del Estado Mayor se ratificaba en el orden de distribución del material, concediendo la máxima prioridad a las academias regimentales, especialmente a las bibliotecas de oficiales y suboficiales.

Como se puede confirmar a través de la documentación consultada y de los expedientes incoados, fue tal la magnitud de la depuración que hubo pueblos en los que, a finales de año, sus escuelas seguían cerradas por no disponer del personal idóneo que reclamaban sus autoridades. Por ejemplo, a comienzos de diciembre seguían cerradas las 9 escuelas de niños del municipio gomero de Hermigua, y el intercambio epistolar entre el jefe de la Sección Administrativa de Primera Enseñanza y el delegado de la Autoridad Militar en la Enseñanza Primaria, no disipaba las dudas sobre la posible contratación de nuevos maestros ${ }^{15}$. Tanto fue así que, con fecha 28 de diciembre, 6 de las 9 escuelas del pueblo seguían cerradas y las 3 restantes abrían intermitentemente con personal afín pero no profesional. Así se mantuvo la situación hasta por lo menos febrero de 1937.

\footnotetext{
14 Documentación de la Secretaría particular y general de la Comandancia Militar de Canarias (1936-1939). Material de enseñanza procedente de incautaciones que deberá distribuirse entre las academias regimentales, escuelas públicas, institutos de segunda enseñanza y establecimientos de beneficencia. Caja 1.788, Carpeta 28. AIMC.

15 Documentación de la Secretaría particular y general de la Comandancia Militar de Canarias (1936-1939). Educación. Caja 1.736, Carpeta 13. AIMC.
} 
En términos parecidos, se mostraban los habitantes del pueblo palmero de Garafía. En una carta dirigida al Comandante Militar de las Islas, exponían el siguiente testimonio que transcribimos literalmente:

Ilmo. general Dolla ¿Es que el espíritu del mal está suelto?, ¿es que no campa ya sino la mentira y que la verdad se disfraza y no se conoce?

Tenemos en el Llano Negro una maestra que era nuestro orgullo por patriota nacionalista y devota de el Ilustre general Franco.

Con calumnias nos la han quitado de entre nosotros, y creo que también por envidia, pues en todo "Garafía" se oía alabar a la Maestra del "Llano Negro".

Tiene una matrícula de 89 niños y siempre está contenta, no cansándole nunca la escuela ${ }^{16}$.

Las madres de familia firmantes no entendían por qué aparecía depurada con una sanción de inhabilitación durante dos años, impuesta con fecha de 28 de noviembre (BOP, 1936f). Según manifestaban, la maestra interina de la escuela mixta de este barrio, Concepción Reyes Expósito, había colocado el crucifijo a comienzos de curso haciéndolo besar a sus alumnos, cantaba himnos patrióticos, había convertido la escuela "en un pequeño cuartel de Falange, pues sus alumnos visten este uniforme y ella también" (sic), etc. Para engrandecer su figura, en el manuscrito enviado al Comandante Militar se criticaba y descalificaba al resto de docentes del municipio sin ningún tipo de consideración ni de reparo. Dichas críticas ocasionaron la apertura de un proceso sin precedentes en la isla de La Palma, tanto para aclarar la conducta moral de la maestra, como de los otros tres docentes del municipio. En efecto, tal fue el empeño de las autoridades por aclarar lo sucedido que en el expediente de 18 páginas iniciado por el subdelegado de la Autoridad Militar de la Enseñanza en la Isla, figuraban declaraciones de padres y madres, de alumnos de la citada maestra y, además, aparecían informes de la alcaldía, cura párroco, comandante del puesto de la Guardia civil, Jefatura de Falange y de Acción

${ }^{16}$ Ibid. 
ciudadana. Salvo la maestra que ya se encontraba residiendo en La Matanza (Tenerife), todos debían rendir cuentas dada la denuncia presentada al máximo exponente de la represión en las Islas. Al mismo tiempo, se citaba al resto de docentes del municipio censurados, a algunos padres y alumnos. El expediente completo se acercaba a los 40 folios. Todos los informes recibidos fueron favorables a los encausados (Manuel Marcos de la Concepción, Araceli Pombrol Gracia, María Brito Guadarrama y Concepción Reyes Expósito); incluso el del cura-párroco consideraba las conductas de los docentes de "inmejorables" aunque no opinaba sobre Concepción Reyes, por no pertenecer a su parroquia. En fin, el 16 de enero de 1937, el Delegado militar de primera enseñanza, José Pérez Andreu, respondía al Comandante militar de Canarias lo siguiente: "Como V.E. verá por lo actuado, que tengo el honor de trasladarle, no aparece culpabilidad alguna contra los maestros. Es criterio de esta Delegación que, a su visita, podrá darse por concluso este expediente"17. Con respecto al levantamiento de la sanción a Concepción Reyes, motivo de toda la polémica, no se decía nada.

En efecto, aunque fue entre noviembre de 1936 y febrero de 1937 cuando se promulgaron las principales disposiciones que regulaban toda la actividad represiva en la enseñanza, a través de la creación de las cuatro Comisiones Depuradoras ${ }^{18}$, en Canarias, por ser zona sometida desde los inicios al golpe de Estado, la depuración comenzó a hacer sus estragos de manera pública y oficial desde los inicios del levantamiento. A partir de ahora comenzaba una nueva fase de consolidación con algunas revisiones de condenas y con la reposición de nuevos docentes en las aulas que cambiaron radicalmente de proceder en sus teorías, prácticas y metodologías educativas ${ }^{19}$.

\footnotetext{
17 Documentación de la Secretaría particular y general de la Comandancia Militar de Canarias (1936-1939). Educación. Caja 1.736, Carpeta 13. AIMC.

${ }^{18}$ Decreto de 8 y Orden de 10 de noviembre de 1936 (BOE, 1936, 27).

19 A partir de noviembre hemos encontrado abundante documentación relativa a las denuncias realizadas por los padres ante los comportamientos "despóticos" de algunos maestros. Golpes, insultos y agresiones formaban parte del quehacer docente cotidiano en Los Cristianos, Los Silos, Santiago del Teide, Santa Cruz de La Palma, etc.
} 


\section{SEGUNDA FASE: MÁS CONTROL, MENOS REPRESIÓN Y ABUNDANTE EXPIACIÓN}

A partir del 20 de enero de 1937 cesaba como Comandante Militar de Canarias Ángel Dolla Lahoz, quien había realizado la mayor persecución sobre los docentes y funcionarios en general, y le sustituía en el cargo Carlos Guerra Zagala. A él se dirigió un grupo de cinco maestras interinas interesadas en que se proveyeran las más de 150 escuelas vacantes que todavía existían en la provincia. "Habiéndose ordenado desde los primeros tiempos del glorioso Movimiento Nacional y por el Gobierno de Burgos la provisión de escuelas vacantes por Maestros titulados, en esta provincia aún no se ha realizado un sólo nombramiento". Para agravar la situación, se había publicado una Orden del gobierno de Burgos en la que se anunciaba concurso de traslados para los maestros en propiedad. Ante ello, continuaban exponiendo las citadas docentes: "Toda vez que aquí no se ha hecho nada, aplicar la Orden de Burgos haría que más de CIENTO CINCUENTA escuelas siguieran sin maestros interinos y casi un número igual de estos continuaran en paro forzoso"20.

El delegado militar de primera enseñanza, José Pérez Andreu, daba la razón a las demandas expresadas por las maestras "teniendo en cuenta que los hechos mencionados son rigurosamente ciertos, y aun agravados por las circunstancias de existir bastantes Escuelas clausuradas debido a esta inhibición en el nombramiento de maestros interinos"21. Todo ello daba cuenta del volumen de escuelas que continuaban sin abrir por las sanciones impuestas a sus docentes y, sobre todo, por la falta de interés de las autoridades para proveerlas. Para aliviar la situación, con fecha de 26 de enero se recibía un telegrama desde Burgos firmado por la Junta Técnica del Estado y el vicepresidente de la Comisión de Cultura y Enseñanza, en el que se daba curso a la petición presentada por las maestras. El mensaje decía: "Puede hacerse

\footnotetext{
20 Documentación de la Secretaría particular y general de la Comandancia Militar de Canarias (1936-1939). Educación. Caja 1.736, Carpeta 13. AIMC.

${ }^{21}$ Ibidem. Comunicaciones enviadas el 22 de enero de 1937.
} 
concurso de maestros interinos. Los propietarios nombrados desempeñarán con carácter interino plaza en propiedad. No se autoriza concurso alguno". Tengamos en cuenta que la burocracia hacía muy lento el proceso de incorporación de los docentes sancionados a las aulas. El levantamiento de las condenas, aceptado por las autoridades provinciales y estatales, terminaba en el despacho del rector de la Universidad de La Laguna que era, en última instancia, quien debía hacerlo efectivo. Por ello, no debe extrañar que al tomar posesión de su cargo el 27 de enero, el rector José Escobedo y González Alberú, mostrara su complacencia al Comandante Militar de Canarias y le ofreciera "colaboración para cuanto afecte al servicio público y particularmente al bien de la enseñanza [primaria]".

Sin embargo, las sospechas de mantener personal en las aulas -o en cargos de responsabilidad- poco afín al régimen, continuaron prodigándose en el tiempo. Uno de los casos más elocuentes y llamativos fue el del inspector de primera enseñanza de esta provincia, Segundo Cuerpo Moreno, quien, a lo largo de 1935, había desempeñado su cargo en Tenerife aunque en el momento de solicitar los informes ya se había trasladado definitivamente a Granada. En el despacho que ofrecía el Gobernador Civil al Delegado de la Autoridad Militar de la Enseñanza, se afirmaba que no "simpatizaba" con el gobernador civil, el lerrouxista Malboysson. Que, además, durante el gobierno republicano había ofrecido un discurso en la Plaza de Toros de esta ciudad con motivo de la celebración de un festival infantil, que no fue el esperado "por los socialistas organizadores del acto en unión de los otros componentes del fatídico Frente Popular". Y que, por último, cuando Izquierda Republicana organizó un viaje de propaganda a esta ciudad del ex-ministro Marcelino Domingo, "este señor desaprobó un manifiesto firmado por el Inspector de Primera Enseñanza, lo que hace creer que los antecedentes del mismo, no son sospechosos". Se consideraba una persona de orden porque sólo se relacionaba con personal del magisterio y porque, en sus ratos libres, dedicaba todo su tiempo a estudiar el preparatorio de la carrera de medicina. Teniendo en consideración todos estos antecedentes, 
concluía el Gobernador civil, se consideraba una "persona honorable"22.

En parecidas circunstancias se instruyó el caso de la Inspectora de Primera Enseñanza de Santa Cruz de Tenerife, María Betancort Ortega, cuyo paradero se desconocía y se denunció en marzo de 1937. El informe de la Inspectora Jefe era el siguiente:

\begin{abstract}
Esta inspección no tiene noticias de que estuviera afiliada a ningún partido político, lo cual hace suponer que no formaba parte, al menos como elemento activo, en ninguna agrupación de esta Naturaleza, si bien es verdad que no se recataba de expresar su devoción por la fracción política que acaudilló Dn. Alejandro Lerroux. Respecto al uso que de su ideología pudo hacer en sus relaciones oficiales con el Magisterio, no consta en esta Dependencia dato alguno de que mezclase ideas políticas en su actuación profesional ${ }^{23}$.
\end{abstract}

Como acabamos de exponer, la barrida de todos los docentes sospechosos, o no adheridos vehementemente al nuevo orden político-social, había sido total. La militarización de la enseñanza, también. No en vano, la prensa de Canarias recogía con orgullo este tipo de razias realizada sobre los maestros:

[...] Franco ha limpiado ya de marxistas al Magisterio, con mano implacable; $\mathrm{y}$ ahora, a sus maestros de confianza, a los verdaderamente católicos y españoles, les llama "creadores del nuevo imperio" y les asegura la categoría moral y social que en justicia les corresponde. Mientras el oro español, robado por el Gobierno de Azaña, corrompe las plumas de viles periodistas, para propalar por todo el mundo infames calumnias, la verdad única y absoluta es ésta: Que España renace victoriosa y magnífica, acaudillada por el mejor de sus hijos, que cuenta para vencer con un ejército de héroes y para forjar la nueva generación, con un magisterio, templado en la prueba de la persecución, profundamente cristiano y reciamente español (DIARIO DE AVISOS, 1937).

22 Ibid. Expediente firmado el 28 de enero de 1937.

23 Informe remitido por la Inspectora Jefe, Susana Villavicencio, al Gobernador Civil de la provincia con fecha 3 de marzo de 1937. Aiep. 
Por tanto, podemos confirmar que a mediados de 1937 se había concluido la depuración de todos los docentes de las Islas, y que sólo faltaba la revisión de condenas que se prolongó hasta bien entrados los años 40. En efecto, para dar cumplimiento a lo ordenado por el Ministerio de Educación Nacional, en un comunicado enviado el 30 de diciembre de 1939, se publicaba la copia "literal" (sic) con la resolución de los expedientes de los maestros nacionales de la provincia. En ella aparecían con separación definitiva del servicio y baja en el escalafón, 26 maestros (sólo una maestra). Inhabilitados perpetuamente para desempeñar escuelas interinas, 9 (dos maestras). Se confirmaron en sus cargos "por no existir pota desfavorable alguna" 15 (7 maestras). Quedaban habilitadas para desempeñar sus escuelas con carácter de interinidad 2. En otra relación instruida por la Comisión depuradora D, de Santa Cruz de Tenerife, tras ser examinada por la Comisión Superior Dictaminadora de Expedientes de Depuración y por la Dirección General de Primera Enseñanza, se añadían dos maestros más a la separación definitiva y a la baja en el escalafón correspondiente. Todos los demás se mantenían sin modificación alguna (BOP, 1936g). En total, 37 maestros separados de sus aulas con baja en el escalafón correspondiente.

$\mathrm{Al}$ mismo tiempo se reponía en sus aulas a los docentes "adheridos a la causa nacional", como fue el caso de Ignacio Padrón, maestro de la escuela nacional de niños número 2 de San Andrés (Tenerife) y, al mismo tiempo, sacerdote de la localidad. Todos los informes solicitados a Falange, Jefe de milicias, alcalde, Guardia civil, Agente marítimo (recordemos que San Andrés es zona costera), eran favorables a su persona. En el informe final, elaborado por la Inspectora jefe, quedaba claro que la precipitación inicial en los procesos depuradores había ocasionado errores que debían ser subsanados:

Esta inspección ha podido comprobar documentalmente que, seguramente por error o precipitación en las personas que informaron, los hechos denunciados no se ajustan a la realidad, no encontrando en el citado maestro que es también Párroco de aquel 
pueblo, causa punible que justifique su destitución ${ }^{24}$.

Sin embargo, no 'estaban' todos los que 'eran' en dichos listados oficiales, porque muchos de los docentes habían impartido sus clases a título particular en sus propias casas o academias. Estos también fueron severamente represaliados. Quizás el caso más ilustrativo sea el del maestro palmero José Miguel Pérez Pérez. Con el título de Bachiller en sus manos emigró a Cuba en 1921, a la edad de 24 años. Allí se convierte en director de la Escuela Racionalista de la Federación Obrera y crea la Agrupación Comunista de La Habana. En 1925 es elegido primer Secretario General del Partido Comunista Cubano. Pocos días después, la policía machadiana lo detiene y lo deporta a España. Ya en La Palma organiza el movimiento proletario y campesino, y pone en marcha la Federación de Trabajadores de la Isla cuya primera labor fue la publicación del semanario Espartaco y la creación de las Juventudes Comunistas. Simultaneaba sus labores políticas con las clases particulares en su Academia Popular Tanausú. "Mi idea es enseñar; enseñar la ciencia, lo cual humaniza y dignifica", solía decir25. En varias ocasiones intentaron cerrar las puertas de su centro, ante lo cual él respondía que "ya es hora de reconocer que en España sobran cuarteles y faltan escuelas; sobran palacios de ricos y faltan viviendas para los pobres"(PÉREZ, 1934). Tras el golpe de Estado, quedaron truncadas sus expectativas de cambio. Fue detenido y trasladado a Tenerife de inmediato. En juicio sumarísimo se le condenó a la pena de muerte, que se hizo efectiva por fusilamiento en el Barranco de El Hierro, en la madrugada del 4 de septiembre de 1936. El sarcasmo oficial volvería a remover sus cenizas cuando, en 1941, tras el anuncio de incoación de expediente de responsabilidades político, se anunciaba su "ignorado paradero" (BOP, 1941). Como él, podría haber una veintena de docentes en la provincia que no figuran en ningún listado oficial.

24 Informe tramitado por la Inspectora Jefe el 15 de diciembre de 1937. Aiep.

25 "Academia Popular Tanausú" para niños y niñas, calle Pedro Poggio, 5. Folleto informativo en el que presentaba la apertura de su centro escolar. Carpeta de ordenanzas, panfletos, etc. Santa Cruz de La Palma, 1926. Archivo La Cosmológica, Santa Cruz de La Palma. 
Pero hay más docentes que añadir a la relación de represaliados que tampoco aparecían en los informes oficiales. Todavía en 1940 se separaba a los maestros de sus cargos por denuncias de los padres, que pretendían que sus hijos aprendieran a leer y escribir los pocos días al año que los enviaban al colegio. Se les acusaba, además, porque "no ondeaba(n) la bandera durante las horas de clase [...] con la unción que acto tan solemne requiere y más en los campos que en la ciudad, porque en ellos, la Escuela es la única institución que da lecciones de patriotismo"26. Fue lo ocurrido, entre otros, a la maestra de la escuela mixta de Ruigómez (El Tanque, Tenerife), María del Carmen Rodríguez de la Cruz. La decisión del inspector de la zona y de la Inspectora jefe, era clara al respecto: "es necesario emplear sanción ejemplar por faltas tan graves cometidas por la Maestra de Ruigómez, en la que no hay la menor señal de arrepentimiento ni vocación para la enseñanza". Y así fue como, recurriendo al apartado $6^{\circ}$ del artículo 161 del Estatuto del Magisterio de 1923 (por tanto, obviando la normativa vigente), se le condenaba a la separación del servicio por un año, con la pérdida de la escuela que regentaba.

Algo parecido fue lo ocurrido a la maestra de la Escuela Nacional Mixta del Malpaís (Candelaria, Tenerife). Según el Secretario de la Junta Municipal de Educación Primaria, el religioso dominico encargado asimismo de la parroquia, Ernestina Carballo Quevedo no cumplía con sus obligaciones de dar clases correctamente "que para que V. E. se dé cuenta hasta qué grado llega la incapacidad de esta funcionaria, al folio figura el Padre Nuestro escrito de puño y letra de la Maestra, delante del Inspector, tardando en efectuarlo media hora justa, y, como se ve, ni el Padre Nuestro sabe escribir". Además, según testimoniaban los vecinos, casi todos analfabetos, "la Escuela era un foco nefasto de indisciplina y perversión infantil". Lo cierto es que después de una extensa denuncia, repleta de calumnias y descréditos, y de ser diagnosticada de "Trastornos nerviosos con perturbaciones del estatismo y dinamismo musculares, y de una considerable astenia mental", a la maestra se le condenó a

\footnotetext{
${ }^{26} 4$ de mayo de 1940. Aiep.
} 
la separación definitiva del magisterio, "con la accesoria del art. 163, reintegrando al Tesoro los haberes correspondientes al mes de marzo del año en curso, que no estuvo al frente de la enseñanza". Tanto ella como su marido, Juan Reyes, habían sido depurados con la suspensión de empleo y sueldo en 1936. No se les perdonaba su reingreso a las aulas ${ }^{27}$.

Otro caso más tuvo lugar en la figura del maestro Antonio Vázquez Nogueira, del que no se observaba "una conducta religiosa absolutamente limpia de toda censura". Y del cual se afirmaba que, al mismo tiempo que tenía abandonada su escuela de San Antonio (Puerto de la Cruz, Tenerife), regentaba otra particular en Arcade (Pontevedra) "calificada tan desfavorablemente que hubo de ser clausurada por la Inspección de $1^{\text {a }}$ Enseñanza de Pontevedra". Por todo lo cual, se le sancionaba con la separación del servicio con pérdida de la escuela durante dos años ${ }^{28}$.

Más grave aún fue la denuncia incoada en enero de 1941 contra el Maestro Antonio Olivera Fuentes (Breña Alta, La Palma) por el Alcalde del municipio. Según testificaba el regidor, la denuncia se debía a que el maestro comenzaba a "exteriorizar su repulsa a los alumnos pertenecientes a Organizaciones Juveniles de Falange Española Tradicionalista y de las JONS, acentuándose aún más hacia aquellos cuyos padres son Falangistas o pertenecientes a partidos de derechas, demostrando por el contrario distinción para los hijos de destacados elementos de izquierda". Supuestamente, había acogido a los expresos del pueblo una vez cumplida su sanción, "que lo fueron por hechos desde luego contrarios al Glorioso Movimiento salvador de España". Y añadía

También el alcalde que suscribe es excombatiente de la Cruzada Nacional, en la que tantos camaradas derramaron su sangre en holocausto por la Patria, con el buen fin de exterminar la horda marxista, que mucho daño la produjo y por todo ello estima, hablando

\footnotetext{
${ }^{27} 9$ de mayo de 1940. Aiep.

${ }^{28} 22$ de agosto de 1940. Aiep.
} 
La denuncia fue enviada al Gobernador civil y éste le dio traslado al Inspector de primera enseñanza. Pese a situarnos en 1941, y tras la sanguinaria fase represora de los comienzos, el trasfondo de la denuncia seguía siendo eminentemente política y no escolar o pedagógica ${ }^{29}$.

Peor suerte tuvieron otros maestros que ya habían figurado en los listados publicados en los correspondientes BOP: Manuel Illada Quintero había sido miembro de la Fete y dirigente del Psoe en La Orotava (Tenerife). Fue deportado a Villa Cisneros (África occidental) de donde se escapó en 1937. Apresado en Valencia, fue trasladado a Tenerife donde se le fusiló el 9 de noviembre de 1940. Carlos Sicilia Pérez, también fue fusilado por orden del Comandante General de Canarias, Ángel Dolla Lahoz, tras la sentencia dictada por el consejo de guerra que lo juzgó. Su muerte tuvo lugar en el Barranco de El Hierro, al igual que la de cientos de canarios, el 7 de diciembre de 1936. El médico que firmó la partida de defunción alegaba una "hemorragia interna" como causa de su óbito. Por su parte, Antonio González Cabrera era miembro destacado del PSOE en La Palma y alcalde del municipio de Garafía, además de maestro. Tras prometerle la libertad si se entregaba voluntariamente, pues se mantuvo huido en los montes de la Isla varias semanas, fue detenido y fusilado en 1937. Ellos fueron algunos de los más de 1600 "desaparecidos" sólo en la Isla de Tenerife (GARCÍA, 1994).

Tras estos acontecimientos tan dramáticos, injustos y reprobables, los maestros adheridos al régimen seguían fieles a sus ideas:

Aquello de dejar al niño en plena libertad de conciencia y de acción es precepto rusoniano, inmejorable para formar ciudadanos díscolos, rebeldes, frente a Dios y frente al Estado [...] Del orden nace la belleza, y de ambos la alegría. Mucho espera el Imperio de la Escuela, porque

2921 de enero de 1941. Aiep. 
es mucho lo que le confía. Le entrega su mañana. Y, por Dios, que sabremos los maestros responder a sus esperanzas (CABALLERO, 1940).

Ante esta devastadora limpieza docente, no es de extrañar que en 1940 sólo el 57\% de los niños comprendidos en edad escolar pudieran asistir a las escuelas públicas de Tenerife. O que en Santa Cruz, de los 9.517 alumnos existentes, sólo asistieran a las escuelas nacionales 2.934 (y 1.776 a las privadas) con lo cual, sólo el 50\% recibían algún tipo de atención escolar (GARCÍA, 1940). O que también pudieran cerrarse las escuelas para poder facilitar a sus docentes la asistencia a los ejercicios espirituales obligados por el régimen y la Iglesia. $\mathrm{O}$ que a los docentes se les denunciara por no cumplir la circular de 5 de marzo de 1938, que les obligaba a asistir a misa con los niños los días de precepto. En su descargo, para este caso concreto, la maestra del barrio rural de Taganana (Tenerife), exponía que de las 65 niñas matriculadas, sólo solían asistir a la escuela, y por tanto a misa, 4 o 5 "a pesar de siempre estarlas requiriendo, no es posible que yo consiga nada, pues los Sres. padres no las mandan30. Exactamente el mismo problema había padecido el maestro de dicho barrio, Julián Rojas de Vera que, con 55 niños matriculados, sólo le asistían a la escuela y a misa 4 o 5 . E insistía: "La culpa de esto la tienen los padres que no obligan a sus hijos a cumplir con lo que manda la Santa Iglesia". Para confirmar su versión, los dos docentes acompañaban el pliego de descargo con un certificado del cura-párrafo que ratificaba sus versiones.

Mientras en los colegios públicos se reducía la asistencia de menores, proliferaron los colegios privados. En 1942 había 42 centros privados en la provincia (16 religiosos y 26 seglares, entre Tenerife y La Palma), y algunos de ellos regentados por personal que sólo disponía del título de bachillerato. El resto de Islas carecían de centros privados por no ser rentables económicamente.

\footnotetext{
${ }^{30}$ Denuncia del inspector de la zona 1 de Santa Cruz de Tenerife, Don Modesto Rodríguez, a la maestra Dña. Estela Hernández, maestra nacional de las niñas de Taganana. 25 de enero de 1940. Aiep.
} 
Otro ejemplo más: todavía en 1951, el director del grupo escolar de niños del Puerto de la Cruz, enviaba una denuncia al Inspector de primera enseñanza de la zona porque "llegado el 29 de octubre, llamado de los "Caídos" el maestro D. Francisco Machado Herrera manifestó a sus compañeros que él creía que, tal día, lo era de clase y que, por tanto, él la daría, aunque el Director mandara lo contrario, como así lo hizo, con solo dos de sus alumnos que asistieron, permaneciendo en el aula aproximadamente un hora, yendo más tarde al funeral, pero en vez de incorporarse al grupo de maestros, lo hizo junto a las autoridades en su calidad de concejal". El director buscaba su apercibimiento, extremo este que no podemos confirmar a través de la documentación manejada. Como tampoco de la denuncia cursada el 28 de julio de 1953 a la maestra Antonia Josefa Mora Mendoza (Macayo, La Gomera) y al maestro Ángel R. Rodríguez Prieto (Ingenio, La Gomera) por sus "conductas inmorales" y "comportamiento escandaloso" al estar embarazada, sin que se hubiera producido el debido y canónico enlace matrimonial. En fin, todavía en 1954 y 1955, bajo el ministerio de Joaquín Ruiz-Giménez, se publicaron las respectivas Órdenes Ministeriales y Decretos por los que se recuperaban los destinos y se tenían en cuenta las puntuaciones en los concursos de traslado para los maestros sancionados en 1936 (BOE, 1954, 1955). Y habían pasado casi 20 años de su reprobación.

\section{CONCLUSIONES}

El peor efecto del golpe de Estado militar fue haberse convertido en sanguinaria realidad y demoledora pesadilla para quienes lo rechazaron desde sus comienzos y, sin poderse defender, engrosaron el listado de desafectos y enemigos del nuevo orden social para el resto de sus vidas. En el caso de los docentes, una de las principales acusaciones para ser separados de sus puestos fue la denominada "gestión nociva de la niñez" (sic) que aparecía en numerosos informes y documentos oficiales. De los 674 maestros públicos en activo en 
1936, fueron sospechosos todos, depurados casi la mitad y sancionados un total de 221 (muchos de ellos, de manera reiterada tras volver a las aulas). A ellos habría que añadir la veintena de docentes que realizaban su labor de manera particular en sus casas o academias particulares que también fueron violentamente apartados de la enseñanza. El porcentaje nos sitúa en torno a un $35,7 \%$ de docentes represaliados en las Canarias occidentales, aunque el reparto por islas eleva alguna de ellas a más del 40\%. Éste fue el caso de La Palma, donde el movimiento obrero y la ideologización popular había sido una nota característica durante todo el período republicano y la llamada "Semana Roja", en la que la Isla se mantuvo fiel al orden constitucional vigente. Tampoco podemos olvidar a los maestros que, debido a su compromiso político, social o sindical no sólo fueron desposeídos de su título universitario e inhabilitados de por vida, sino que fueron asesinados en juicios sumarísimos sin ningún tipo de garantías procesales. De hecho, había una consigna 'preventiva' y 'profiláctica' en la actuación de las nuevas autoridades que consistía en condenar antes de detener, en detener antes de sospechar y en sospechar antes de comprobar; después, ya se vería.

$\mathrm{Al}$ otro lado quedaban los alumnos. Miles de niños que, habituados a la escolarización tras el enorme esfuerzo realizado por las autoridades republicanas en las Islas, se vieron nuevamente abocados a la ignorancia, la vagancia, la mendicidad o los trabajos a destajo para mantener a las familias, si alguno de sus progenitores había sido acusado de desafecto al nuevo régimen. El revés había sido total y sus consecuencias humanas incalculables; en los ámbitos docentes y pedagógicos, aunque no sólo en ellos, la tragedia fue parcialmente superada - esto es, oficializada, exhibida y aclamada- a través de la tergiversación, la mediocridad, la violencia y exaltados y excéntricos actos de fe.

\section{REFERENCIAS}

ALted VIGIL, Alicia. Política del nuevo Estado sobre el patrimonio 
cultural y la educación durante la Guerra Civil Española. Madrid: Dirección General de Bellas Artes y Archivos, Centro Nacional de Información Artística, Arqueológica y Etnológica, y Ministerio de Cultura, 1984.

ANAYA HERNÁNDEZ, Luis Alberto et al. La represión franquista en la enseñanza en la provincia de Las Palmas (1936-1939). Revista Guiniguada, Las Palmas de Gran Canaria, ULPGC, 3, p. 203-221, 1987.

BOLETín OFICIAL DEL ESTADO (BOE). 18 de julio de 1945. Ley 17 de julio de 1945, 199.

BOLETÍN OFICIAL DEL ESTADO (BOE). 10 de diciembre de 1936, 52.

BOLETÍN OFICIAL DEL ESTADO (BOE). 11 de noviembre de 1936, 27.

BOLETÍN OFICIAL DEL ESTADO (BOE). 18 de agosto de 1954.

BOLETÍN OFICIAL DEL ESTADO (BOE). 29 de marzo de 1955.

BOLETÍN OFICIAL DE LA PROVINCIA (BOP) DE SANTA CRUZ DE TENERIFE. 20 de julio de 1936a, 87.

BOLETÍN OFICIAL DE LA PROVINCIA (BOP) DE SANTA CRUZ DE TENERIFE. 18 de septiembre de 1936b, 113 .

BOLETÍN OFICIAL DE LA PROVINCIA (BOP) DE SANTA CRUZ DE TENERIFE. 23 de septiembre de 1936c, 115.

BOLETÍN OFICIAL DE LA PROVINCIA (BOP) DE SANTA CRUZ DE TENERIFE, 9 de septiembre de 1936d, 109.

BOLETÍN OFICIAL DE LA PROVINCIA (BOP) DE SANTA CRUZ DE TENERIFE, 9 de noviembre de 1936e, 135 .

BOLETÍN OFICIAL DE LA PROVINCIA (BOP) DE SANTA CRUZ DE TENERIFE, 9 de diciembre de 1936f, 148.

BOLETÍN OFICIAL DE LA PROVINCIA (BOP) DE SANTA CRUZ DE TENERIFE, 31 de enero de 1936g, 14.

BOLETÍN OFICIAL DE LA PROVINCIA (BOP) DE SANTA CRUZ DE TENERIFE, 29 de septiembre de 1941, 117.

CABALLERO LÓPEZ, Fernando. Escuela azul. Escuela Azul, Órgano Oficial de la Delegación Provincial del SEM. 31, 10 de febrero de 1940.

CABRERA, Miguel Ángel. (Ed.). La Guerra Civil en Canarias. Tenerife: 
Francisco Lemus editor, 2000.

CASANOVA, Julián. La iglesia de Franco. Barcelona: Crítica, 2005.

CLARET MIRANDA, Jaume: El atroz desmoche. La destrucción de la universidad española por el franquismo, 1936-1945. Barcelona: Crítica, 2006.

DIARIO DE AVISOS, "Soldados y Maestros". 12 de mayo de 1937, 17.650.

FERRAZ LORENZO, Manuel La Palma: sociedad, educación y cultura (19311939). Tenerife: Gobierno de Canarias, Cabildo Insular de La Palma y Centro de la Cultura Popular Canaria, 1997.

FERRAZ LORENZO, Manuel. La educación como símbolo de poder para la iglesia en España durante la etapa franquista. La Labor pastoral y pastoril de Fray albino Menéndez-Reigada, Obispo de Tenerife (1925-1946). In: DE CARVALHO, Carlos Henrique y GONÇALVES NETO, Wenceslau (Org.). Estado, igreja e educação: o mundo ibero-americano nos séculos XIX e XX. Editora Alínea: Brasil, 2010. p. 117-141.

FONTANA, Josep. España bajo el franquismo. Barcelona: Crítica, 1986.

GACETA DE TENERIFE. Santa Cruz de Tenerife, 30 de octubre de 1936, 8.674.

GARCÍA LUIS, Ricardo. La justicia de los rebeldes. Los fusilado en Santa Cruz de Tenerife (1936-1940). Tenerife: Baile del sol, 1994.

GARCÍA SANJUÁN, Cándido. El problema escolar en Tenerife. Escuela Azul, Órgano Oficial de la Delegación Provincial del SEM, 52, 10 de septiembre de 1940.

GRAHAM, Helen. Breve historia de la guerra civil. Madrid: Espasa-Calpe, 2006.

GRANA GIL, Isabel et al. Controlar, seleccionar y reprimir. La depuración del profesorado de Instituto en España durante el Franquismo. Madrid: Instituto de la mujer y para la igualdad de oportunidades, 2005.

HERNÁNDEZ HERNÁNDEZ, José Manuel. La represión franquista sobre los maestros en la provincia de Santa Cruz de Tenerife. Revista Periferia, Tenerife, Aula de Cultura de Geografía e Historia, 4, p. 93-105, 1989.

INSTITUTO DE ESPAÑA. Menéndez Pelayo y la educación nacional. Madrid: Instituto de España, 1938. 
JULIÁ, Santos. Víctimas de la guerra civil. Madrid: Temas de Hoy, 1999.

LEÓN ÁlVAREZ, Aarón. (Coord.). El franquismo en Canarias. Actas del Encuentro de Historia sobre el franquismo en Canarias. Tenerife: Le Canarien Ediciones e Instituto de Estudios Canarios, 2014.

LEÓN ÁlVAREZ, Aarón (Coord.). La retaguardia de Franco. Personal político y poder local en las Canarias Occidentales. 1936-1961. Tenerife: Instituto de Estudios Canarios, 2016.

MAYORDOMO, Alejandro; FERNÁNDEZ SORIA, Juan Manuel. Vencer y convencer. Educación y política, España 1936-1945. Valencia: Universitat de València, 1993.

MORENTE VALERO, Franciso. La escuela y el Estado Nuevo. La depuración del magisterio nacional (1936-1943). Valladolid: Ámbito, 1997.

MORADIELLOS, Enrique. Francisco Franco: Crónica de un caudillo casi olvidado. Madrid: Biblioteca Nueva, 2002.

NEGRÍN FAJARDO, Olegario. Memoria histórica y educación en Canarias (1936-1942). Depuración y represión del Magisterio en la provincia de Las Palmas. Las Palmas de Gran Canaria: Cabildo de Gran Canaria, 2010.

PAYNE, Stanley George. El primer franquismo 1939-1959. Los años de la autarquía. Madrid: Editorial Historia 16. Temas de Hoy, 1977.

PÉREZ PÉREZ, José Miguel. Vivienda y educación. Espartaco, Santa Cruz de La Palma, 211, 15 de septiembre de 1934.

PRESTON, Paul. Franco. Caudillo de España. Barcelona: Mondadori, 1998.

REIG TAPIA, Alberto. Violencia y terror: estudios sobre la guerra civil española. Madrid: Akal, 1990.

RIVAS GARCÍA, Ramiro. La Guerra Civil en Tenerife (1936-1939). 2 Tomos. 2015. Tesis (Doctorado) - Departamento de Historia, Universidad de La Laguna, 2015.

VIVES PI-SUNYER, Carles. El personal político de Franco (1936-1975). Barcelona: Vicens Vives, 1978.

VARIOS AUTORES. La cultura bajo el franquismo. Barcelona: Ediciones de Bolsillo, 1977. 
MANUEL FERRAZ LORENZO es profesor Titular de Teoría e Historia de la Educación en la Universidad de La Laguna (España). Autor y coautor de varios libros, monografías y artículos de investigación publicados en revistas españolas, europeas, norteamericanas y latinoamericanas. Sus temas de interés versan sobre Teoría e Historia de la Educación y de la Pedagogía. Pertenece al Departamento de Historia y Filosofía de la Ciencia, la Educación y el Lenguaje. Actualmente es Investigador Principal (o director) del Proyecto de I+D+i concedido por el Ministerio de Economía y Competitividad de España cuya referencia es EDU2016-78143-R.

E-mail:mferraz@ull.edu.es

(b) http://orcid.org/0000-0001-7664-4353

Recebido em: 10 de abril de 2018

Aprovado em: 06 de maio de 2019

Revista História da Educação - RHE

Associação Sul-Rio-Grandense de Pesquisadores em História da Educação - Asphe

Artigo de acesso aberto distribuído nos termos de licença Creative Commons. 